\title{
Recurrent Lumbar Disc Herniation: A Narrative Review
}

\author{
Ghanshyam Kakadiya ${ }^{1}$, Viraj Gandbhir ${ }^{1}$, Kshitij Chaudhary ${ }^{1,2}$
}

\section{Abstract}

This narrative review aimed to identify various risk factors of recurrent lumbar disc herniation (rLDH) post-discectomy and its management. The rLDH has remained a challenging problem for spine surgeons. The incidence of rLDH is reported widely from $1 \%$ to $21 \%$. Many possible patient-related, disc-related, and surgery-related risk factors may predispose the patient to rLDH. Moreover, the clinical and radiological diagnosis of rLDH can be challenging. Once the diagnosis is confirmed, and alternative diagnoses for leg pain have been ruled out, a course of initial non-operative treatment can be attempted. Compared to primary $\mathrm{LDH}$, non-operative treatment is less likely to succeed in $\mathrm{rLDH}$, possibly due to the associated epidural fibrosis and scarring. Various surgical options can be considered, including revision discectomy and fusion. Revision discectomy is usually the primary choice of surgery for the first recurrence. A fusion procedure can be chosen for those who have repeated reherniations or significant associated back pain. Precise patient selection is a must to achieve excellent surgical outcomes.

Key words: Lumbar disc herniation; Recurrent herniation; Discectomy; Risk factors; Epidural fibrosis; Narrative review.

\section{Introduction}

Lumbar disc herniation (LDH) is one of the most common spine disorders in the young population [1]. Patients who fail to respond adequately to conservative treatment are usually treated with a discectomy. Post-discectomy complications are rare, and one of them is a recurrent Lumbar disc herniation $(\mathrm{rLDH})$ [2]. The incidence of $\mathrm{rLDH}$ is reported widely from $1 \%$ to $21 \%$. This wide variation is primarily secondary to the vague definition of what constitutes as a $\mathrm{rLDH}$. However, the most commonly accepted rate is around 5\% [3, 4]. Apart from $\mathrm{rLDH}$, post-operative disc herniation symptoms can be caused by epidural fibrosis, hematoma, infection, iatrogenic instability, nerve root injury, or arachnoiditis. This narrative review aims to give a general overview of rLDH and discuss various associated risk factors and treatment for $\mathrm{rLDH}$.

\section{Definition of rLDH}

The diagnosis of rLDH is clinical and should be supported by imaging evidence. Furthermore, the herniated disc material should be at the same level, ipsilateral, or contralateral, in a patient who reports a pain-free interval of at least 6 months since the primary surgery. The clinical syndrome of radicular pain should be concordant with $\mathrm{rLDH}$, as identified on the magnetic resonance imaging (MRI) [5]. The 6-month time interval should not be considered a strict limit as rLDH could occur within this period. Some authors also put an upper limit to the diagnosis of rLDH as 18 months, suggesting that leg pain beyond this time is more likely due to a de novo herniation [6].

\section{Risk Factors}

The pathogenesis of $\mathrm{rLDH}$ is unclear $[3,4,5]$. Many risk factors are thought to contribute to $\mathrm{rLDH}$. There is a lack of consensus regarding the relative importance of these risk factors, and many are unsubstantiated. However, the factors contributing to rLDH seem to be multifactorial.

\section{Patient-related factors}

Age and gender

There is a controversy in the literature regarding the effect of age and gender on rLDH. Keskimaki et al. reported a significantly higher risk for young patients aged $<50$ years compared with the older group [6]. In contrast, Jansson et al. reported a lower risk of reoperation than those young $(<40$ years) [9]. Shimia et al. [8] and Kim et al. [10] reported that a

\footnotetext{
1 1 'Department of Orthopaedics, Topiwala National Medical College \& BYL Nair Hospital, Mumbai, Maharashtra, India ${ }^{2}$ Department of Orthopaedics and Spine Surgery, Sir HN Reliance Foundation Hospital and Research Center, Mumbai, Maharashtra, India

(C) 2020 | Back Bone: The Spine Journal (The Official Journal Of "Spine Association Of Gujarat") | Available on www.backbonejournal.com | doi:10.13107/bbj.2020.v01i01.010 This is an Open Access article distributed under the terms of the Creative Commons Attribution Non-Commercial License (http://creativecommons.org/licenses/by-nc/3.0) which permits unrestricted noncommercial use, distribution, and reproduction in any medium, provided the original work is properly cited.
} 
higher incidence of rLDH exists in males. Overall, the individual contribution of these unmodifiable risk factors does not seem to be significant.

Body mass index (BMI)

A high BMI is a risk factor for rLDH. Meredith et al. reported that patients with $\mathrm{BMI} \geq 30$ were 12 times more likely to have an rLDH and require surgery compared to patients with a low $\mathrm{BMI}[11]$.

\section{Smoking}

Detrimental effect of smoking on the health of the intervertebral disc is well reported in the literature [12]. Smoking has a negative effect on the healing of annulus, leading to a higher risk of $\mathrm{rLDH}$ [13]. Miwa et al. reported that the incidence of rLDH is $18.5 \%$ in smokers compared to nonsmokers [14].

\section{Diabetes}

The intervertebral disc of diabetic patients has low sulfate integration into the glycosaminoglycan molecules and low proteoglycans. Both the sulfation and proteoglycans are known to strengthen the disc. A reduction of these molecules may predispose to rLDH [15]. Mobbs et al. reported higher rates of $\mathrm{rLDH}$ and reoperation in people with diabetes compared to non-diabetics (28\% vs. $3.5 \%)$ [ 16$]$.

\section{Occupation}

Shimia et al. found in their study that there was a statistically significant relationship between the cumulative exposure to weight lifting or carrying heavyweight [8] and also with extreme forward bending, and LDH [17].

\section{Morphology of the primary disc herniation \\ Level of herniation}

The most common affected levels for primary and $\mathrm{rLDH}$ were $\mathrm{L} 4 / 5$ and L5/S1. The literature does not suggest a specific level as a predictor for $\mathrm{rLDH}[8,18]$.

\section{Type}

The type of the previous disc herniation affects the risk of rLDH. Patients with disc protrusion do not have a discrete defect in the annulus, but rather a thinned out and stretched annulus. On the contrary, the disc extrusion defect is limited and can probably heal more effectively. Morgan-Hough et al. [19] suggested that disc protrusion is more significant as a predictor for rLDH compared to disc extrusion.

\section{Size of annular defect}

Annular defect acts as a path for a loose fragment to come out of the disc. There is a high chance of rLDH in significant annular defects [6].
Other radiological features

Intervertebral disc height

Larger disc height before discectomy could lead to a higher disc height decrease after nucleus removal and increased segmental mobility, influencing $\operatorname{rLDH}[1,20]$. Yaman et al. reported a significant correlation between disc height and the prevalence of rLDH $[18]$.

\section{Lumbarlordosis}

Post-discectomy decreased lumbar lordosis was associated with the rLDH. Suboptimal lumbar lordosis disturbs normal biomechanics of the spine, sagittal spinal alignment, and body weight distribution, and this may increase disc degeneration and the risk of rLDH $[20,21]$.

\section{Segmental instability}

Post-discectomy instability may increase rLDH. Patients with an intervertebral motion of $>10$ had a higher recurrence rate $(26.5 \%)$ compared with those with $<10(4.1 \%)[1]$.

\section{Lower Pfirrmann degeneration grades}

Incidence of rLDH was lower in discs with Pfirmann degeneration Grades I, II, and VI than in discs with Grades III, $\mathrm{IV}$, and $\mathrm{V}[10,20,22]$.

\section{Modic endplate changes}

Endplate changes may also contribute to decreased collagen fiber attachment to the annulus and is theorized to explain the increased risk of rLDH $[10,20]$.

\section{Surgical technique}

\section{Fragmentectomy versus aggressive discectomy}

The fragmentectomy is the removal of an extruded disc with the preservation of normal disc material and requires little or no annular incision for fragment removal. Conventional aggressive discectomy is a removal of an extruded disc with normal disc material. Fragmentectomy or controlled discectomy has more chances of rLDH. Carragee et al. [5] showed that the aggressive removal of remaining disc material might decrease the risk of reherniation, but the overall outcome was less satisfactory due to higher back pain.

\section{Annularincision}

McGirt et al. [3] and Kim et al. [10] proved that the outer layer of the annulus has a minor capillary network with the potential to heal annular defects instead of the completely avascular inner annulus. Hence, a "slit-like incision" versus a "rectangular box annulotomy," has a higher likelihood for annular membrane healing and maintenance of some annular integrity [23]. 


\section{Saline lavage}

Saline lavage through annular opening may deliver loose disc fragments for removal out of the disc. Ellenbogen et al. demonstrated that disc space lavage with normal saline was associated with a low rLDH rate [24].

\section{Post-operative activity or return}

There is a fear that early return to work may predispose to an $\mathrm{rLDH}$. However, there is no evidence of his effect. Instead, studies have shown that post-discectomy early return to regular activity is beneficial rather than harmful $[25,26]$. Postoperative restriction of activity should be advised only until the wound has healed.

\section{Evaluation of rLDH}

\section{Clinical presentation}

The patient typically presents with leg pain in the same distribution as experienced during the index herniation. As discussed above, patients with rLDH have a symptom-free period after the primary lumbar discectomy. The longer this symptom-free period, the more likely the pain is due to new disc herniation. The clinical picture is not always clear and easy to diagnose. Post-discectomy back pain with referred pain into the leg needs to be differentiated from true radicular pain. The differential diagnoses in a post-discectomy patient who returns with recurrence of symptoms include scar tissue, epidural fibrosis, arachnoiditis, and infection.

Patients with rLDH may not experience the same leg pain as previously experienced as the new recurrence herniation may differ in size, location, and migration. Besides, the surrounding scarring may reduce the nerve root's mobility and alter the sensation of pain. For similar reasons, the patients may not always have classical root tension signs. Recurrent disc herniations have not been shown to have a higher rate of neurological deficits than primary disc herniations (Fig. 1).

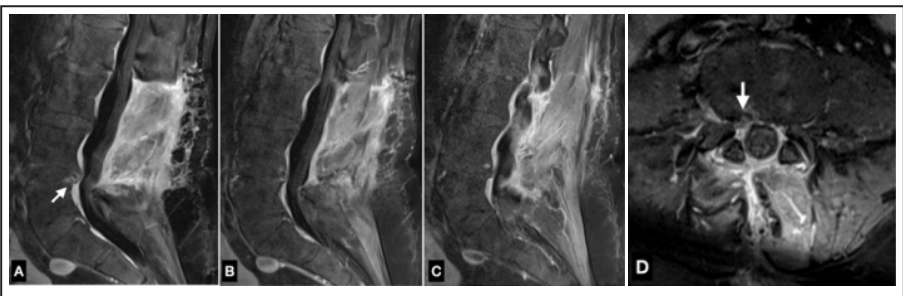

Figure 1: A 55 years old with right leg pain presented 9 months after L3-4 laminectomy. L4-5 recurrent disc herniation on the right side (white arrow) is noted on these T1-WI fat-suppressed post-contrast images. In these images, contrast enhancement of the scar is easily distinguished from epidural fat which is suppressed. Note the peripheral enhancing rim around the disc material in Figure A. The disc material itself is hypointense.

\section{Radiographs}

$\mathrm{X}$-rays are the only radiographic investigation that can be done under physiological loading to assess instability. They can be useful to reveal occult instability secondary to iatrogenic spondylosis or accelerated disc degeneration.

\section{Computed tomography (CT) scan}

CT scans with intravenous contrast are less accurate than MRI in differentiating rLDH from fibrosis. It is also not sensitive enough to detect other pathologies such as root inflammation, arachnoiditis, or infection that can also cause leg pain. CT scan can be useful in chronic herniation with superimposed spinal stenosis to evaluate bony compression.

\section{MRI}

The gadolinium-enhanced MRI is the investigation of choice for $\mathrm{rLDH}$. Interpreting postoperative MRI scans can be challenging, especially in the acute post-operative period. The sequence best suited to differentiate $\mathrm{rLDH}$ from peridural fibrosis is a fat-suppressed T1-WI (pre- and post-Gadolinium). Other sequences recommended in the protocol are sagittal and axial T1-WI and T2-WI images.

Natural evolution of MRI changes post-lumbar discectomy One must be aware of the natural course of evolution of postoperative MRI features following lumbar discectomy to distinguish $\mathrm{rLDH}$ from post-operative changes. Early $(<2$ months) MRI features post-discectomy should be interpreted with caution, as they can mimic pre-operative disc herniation image, especially if the MRI is without contrast. The surgical disruption of the annulus and the collection of hematoma, edema, granulation, and possibly Gelfoam pieces mimic the appearance of a space-occupying lesion like a disc herniation. Contrast-enhanced images show a robust homogenous enhancement of this mass, indicating that the "mass" is nothing but inflammatory tissue. However, some studies have detected rLDH in $24 \%$ of asymptomatic patients within 6 weeks of surgery [27]. The same group of investigators has demonstrated that asymptomatic patients following discectomy almost always show a mass effect with a deformation that is usually never more than $25 \%$ of the thecal sac area [28]. In the acute period, the disc shows a high signal intensity band extended to the site of the annulotomy. The endplates may show enhancement for 6-18 months in $20 \%$ of patients after surgery [29]. Usually, MRI starts showing a healing response 6 months after discectomy. The signal in the disc becomes low-intensity. The acute inflammatory mass effect shrinks but may persist as a scar that occupies space. However, scarring tends to pull the dura toward it compared to an rLDH that tends to push the dural sac away. Scar shows a weaker enhancement to contrast compared to the acute 
inflammatory mass [31]. Asymptomatic patients detected to have $\mathrm{rLDH}$ in the post-operative scans may regress spontaneously by phagocytosis induced by the surrounding inflammatory tissue. Nerve root enhancement, commonly detected in the acute postoperative period, resolves by 6 months.

\section{rLDH versus epidural fibrosis}

The distinction between rLDH and epidural fibrosis is crucial as the revision surgery for scar is rarely successful. In fact, more surgery begets more scars. The difficulty in differentiating the two is exemplified by the discordant intraoperative findings in $18-33 \%$ of surgically proven cases [7]. On unenhanced images, scar and rLDH may appear similar as both can have a mass effect displacing the thecal sac. The difference becomes apparent in contrast-enhanced images (Fig. 1). An rLDH does not enhance as the disc material has no blood supply. The periphery of the rLDH may show rim enhancement, which represents either scarring or inflammation surrounding the disc material. However, delayed scans can enhance the disc as the contrast diffuses inside, which can be mistaken for a scar. Delayed contrast enhancement of extruded disc is more commonly seen in chronic rLDH as the surrounding inflammation progressively creeps inside the disc. Hence, it is imperative to scan the patient within $5 \mathrm{~min}$ of contrast injection. In contrast, scars show moderate uniform enhancement as they have vascular supply. The difference between $\mathrm{rLDH}$ and epidural fibrosis is enumerated in Table (Table 1).

\begin{tabular}{|c|c|c|}
\hline MRI features & Fibrosis & Recurrent disc herniation \\
\hline T1-WI & Isointense & Hypointense \\
\hline T2-WI & Isointense & Hypointense \\
\hline \multirow[t]{2}{*}{$\mathrm{T} 1-\mathrm{WI}+\mathrm{Gad}$} & $\begin{array}{l}\text { Immediate } \\
\text { homogeneous } \\
\text { enhancement }\end{array}$ & $\begin{array}{l}\text { Disc material shows no enhancement. } \\
\text { But may enhance peripherally }\end{array}$ \\
\hline & & $\begin{array}{l}\text { Diffuse enhancement if post-contrast } \\
\text { imaging is delayed (>10 min) }\end{array}$ \\
\hline \multirow[t]{2}{*}{ Margins } & Irregular & Smooth \\
\hline & Dura looks retracted & Dura looks displaced \\
\hline Mass effect & $\begin{array}{l}\text { May be present but } \\
\text { minimal }\end{array}$ & Present \\
\hline Location & $\begin{array}{c}\text { Lateral recess, } \\
\text { posterior to anterior }\end{array}$ & $\begin{array}{c}\text { Ventral or lateral to the dura but also } \\
\text { can have a migrated or sequestered } \\
\text { fragment }\end{array}$ \\
\hline \multicolumn{3}{|c|}{ MRI: Magnetic resonance imaging } \\
\hline
\end{tabular}

\section{Diagnosticinjection}

Patients with atypical pain and controversial MRI findings may be subjected to diagnostic nerve root blocks. However, the success of the nerve block frequently depends on the expertise of the clinician. Therefore, it is imperative that the documentation of the needle position and the radiographic contrast spread before the steroid injection is available for interpreting the post-injection symptoms. If the needle placement is anatomically accurate with a good spread of the contrast and the patient informs of more than $80 \%$ pain relief after the procedure for about 4-6 h, then it can be reasonably concluded that the pain's origin is the level that is injected. This may help the surgeon choose a surgical plan.

\section{Management of rLDH \\ Conservative treatment}

As with primary $\mathrm{LDH}$, conservative treatment is the mainstay in the early stages of radicular pain due to rLDH. NSAIDS, oral steroid taper, or neuropathic medications can be used for pain relief. Similarly, physical therapy can be attempted. However, neither the medications nor physical therapy has been shown to alter the natural history of radicular pain due to disc herniation. Therapeutic nerve root blocks also can be offered to the patient, but compared to steroid injections for primary discherniations; they are less likely to be effective.

A meta-analysis found that the incidence of reherniation (5.5\%) was similar to the incidence of reoperation for the $\mathrm{rLDH}(5.2 \%)$, suggesting that the majority of the symptomatic rLDH lead to surgery $[8,31]$. Thus, it can be interpreted that the natural history of $\mathrm{LDH}$ is not as favorable as primary $\mathrm{LDH}$. The scar may surround the nerve roots and cause symptoms through neural tension, decreased axoplasmic transport, restriction of blood flow, or venous return. This scar is hypothesized to be the reason for suboptimal outcomes of conservative therapy in $\mathrm{rLDH}$.

Despite this, conservative treatment is always offered to patients who present with symptomatic rLDH without significant neurological deficits. However, the conservative treatment duration need not be quite as prolonged, especially if the patient complains of increasing pain despite medications and nerve blocks. The traditional recommendation of 6 weeks of conservative therapy may not be strictly followed in $\mathrm{rLDH}$, knowing that the natural history is not as favorable as primary herniation.

\section{Surgical treatment}

The decision to operate an rLDH should not be made in haste. Patients with unusual and imprecise symptoms should be approached with caution. MRI tends to over-diagnose rLDH, and correlating the imaging findings with the clinical picture is not always straightforward. The ability to predict a good 
response to reoperation depends on choosing the right patient for the procedure, rather than the surgical technique. A patient with classical radicular pain pattern with root tensions signs and a reasonable symptom-free period after index procedure can be offered a reoperation if the MRI shows concordant compressive disc herniation. The choice of surgery is a repeat lumbar discectomy or instrumented fusion [20,32]. In the literature, the majority reoperations for $\mathrm{rLDH}$ are reported as revision discectomies, and only 5\% are fusions [19]. The second recurrence, however, is more likely to be treated with fusion.

\section{Revision discectomy}

The options available are conventional microdiscectomy or minimally invasive tubular discectomy, and they seem to have similar outcomes. However, epidural scarring due to the

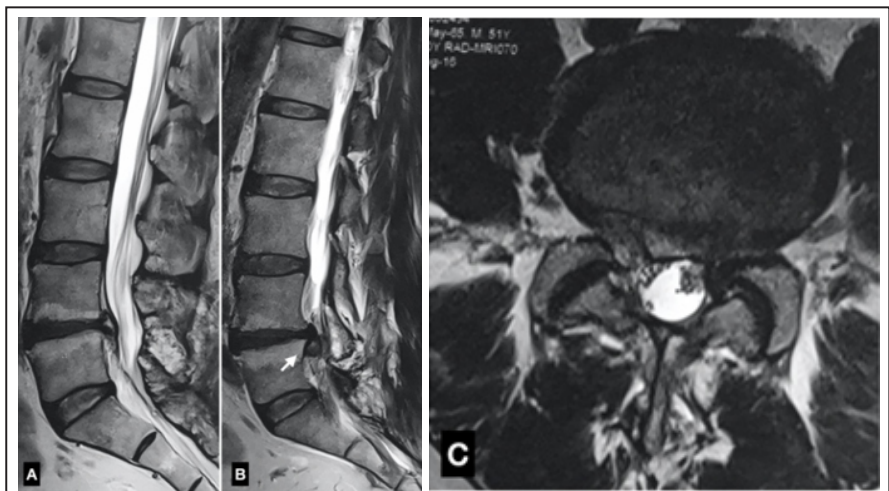

Figure 2: A 51-year-old man with the left leg pain due to a recurrent disc herniation after 2 years of primary discectomy as diagnosed on these sagittal and axial T2-WI images. On the left parasagittal T2-WI magnetic resonance imaging (B) the disc herniation appears to have migrated inferiorly (white arrow). Fibrosis and scarring generally will not be noted with this pattern of migration.

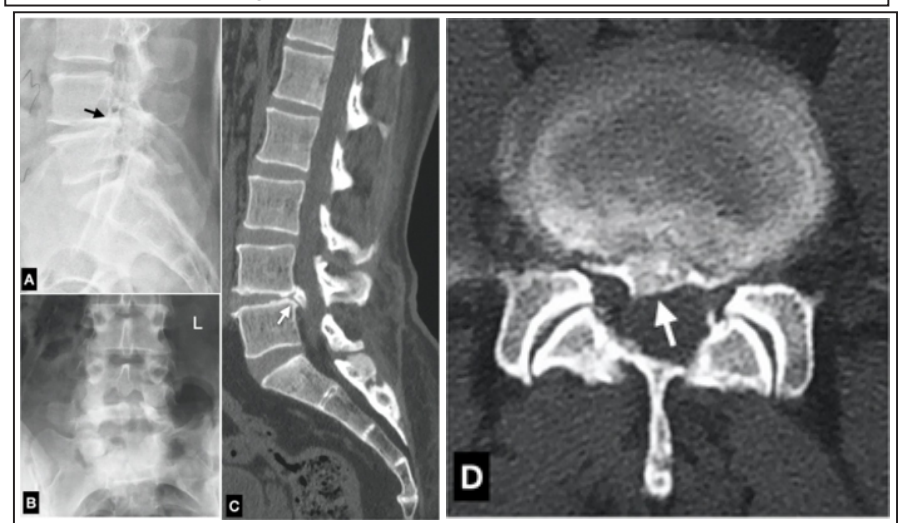

Figure 3: Continued - The radiographs of the patient showed calcification at the previously operated L4-5 level (black arrow). This prompted a computed tomography scan which showed a centrally calcified disc (white arrow). The disc fragment was found to have extruded from an annular tear on the inferior edge of this disc calcification. previous surgery can make minimally invasive surgery challenging, with a steep learning curve being required to achieve comparable results. Alternatively, percutaneous endoscopic discectomy has been reported to have some advantages over interlaminar approaches such as fewer complications, blood loss, and shorter hospital stay [33]. However, there are some reports of a higher re-recurrence rate of up to 7\% following PELD [34]. Nevertheless, the outcomes of revision discectomy have been found to be inferior to primary discectomy in many studies [35]. Others have reported similar outcomes $[21,32,36]$.

\section{Fusion}

Fusion is usually considered for a second or a third recurrence. It may also be considered in patients with significant low back pain, especially if they have radiographic instability. The choice of fusion also depends on the extent of bone removal during the primary discectomy. If the index surgery was a wide laminectomy, then during a revision, it is likely that further bone removal will compromise the stability of the motion segment. The surgeon may choose to perform fusion in this situation. If the decompression of the nerve root involves sacrificing the motion segment's stability, then it is prudent to fuse. Several options for fusion are available (PLF-

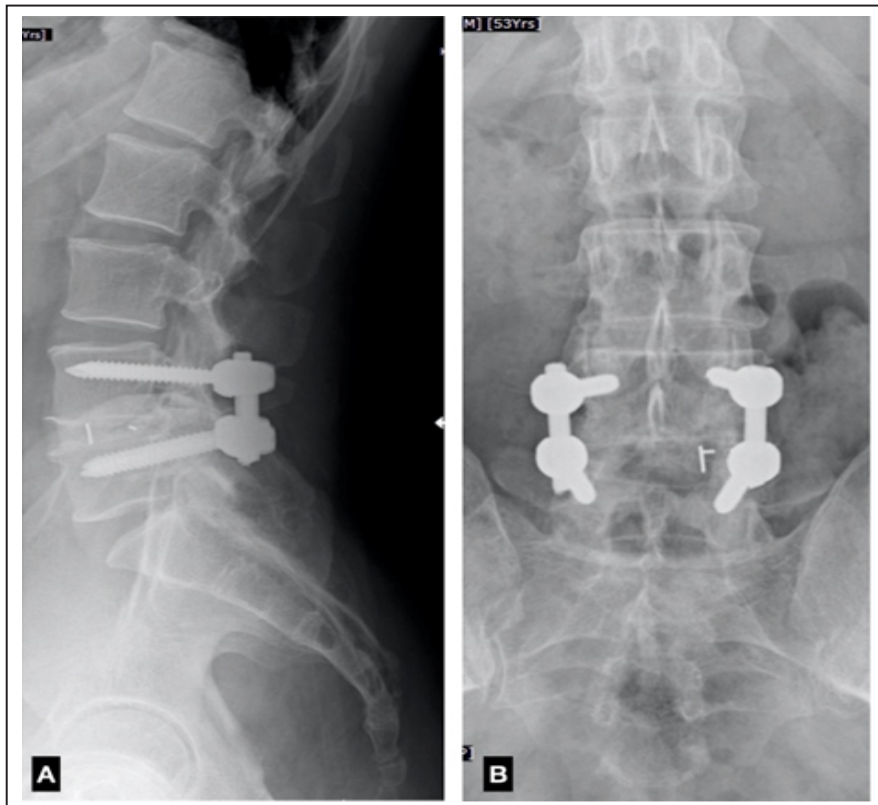

Figure 4: Continued - Patient failed conservative treatment including epidural injections and subsequently underwent an L4-5 TLIF in view of the calcification of the disc. A facetectomy was necessary to achieve removal of the centrally calcified disc avoiding excessive retraction of the nerve root. Hence, TLIF was performed even though this was the patient's first recurrence. The patient was relieved of the leg pain after the surgery. These are 2-year follow-up radiographs showing fusion. 
Pasterolateral Fusion, PLIF- Posterior Lumbar Interbody Fusion, TLIF- Transforaminal Lumbar Interbody Fusion, ALIF- Anterior Lumber Interbody Fusion, XLIF- lateral Lumber Interbody Fusion etc.), and none have proven to be superior to the other.

Choosing a fusion procedure for the first recurrence is controversial. While a fusion procedure carries a lesser risk for reherniation and post-operative back pain, the decision needs to be weighed carefully against complications that can arise secondary to instrumented fusion [37]. Mroz et al. conducted a survey and concluded that experienced surgeons with higher patient load preferred revision microdiscectomy to treat rLDH, while young surgeons preferred interbody fusion [38]. A surgeon may choose from a myriad of procedures, which depends on their training and experience. From the available evidence, it can be surmised that different surgical procedures to treat recurrent disc herniation yield similar functional and pain improvement. Studies with different modalities of treatment for $\mathrm{rLDH}$ and their outcome are enumerated in Table 2(Table 2).

Table 2: Studies with different modalities of treatment for rLDH and their outcome

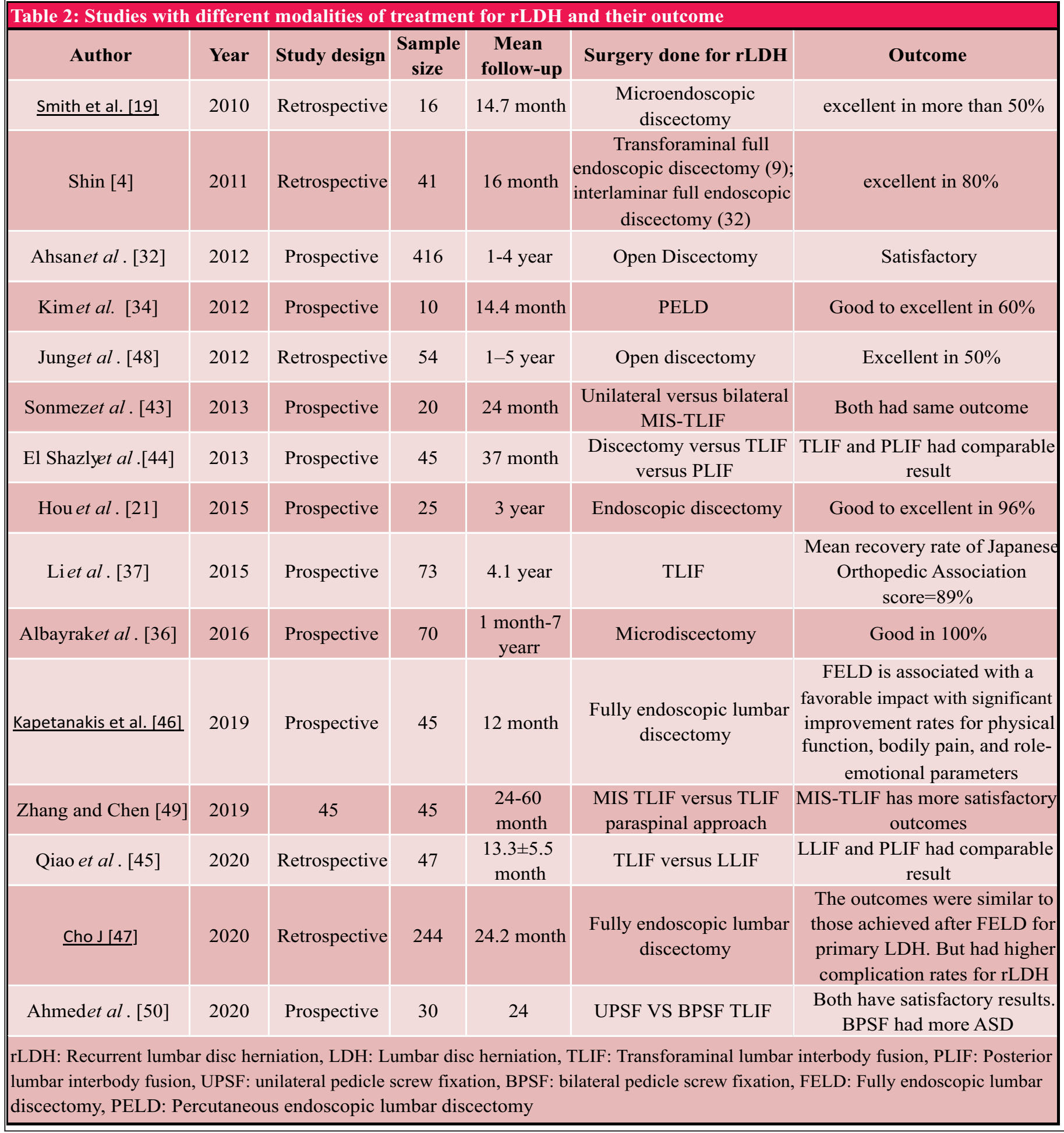




\section{Illustrative case}

A 51-year-old male was treated with an L4-5 TLIF for a recurrent disc herniation 2 years after discectomy. The clinical presentation, imaging findings, and treatment are described in Figs. 2-4.

\section{Prevention}

\section{Annular repair}

Researchers are attempting to develop techniques and devices to repair the annular defect to restrict the disc material from reherniating. Recently, innovative technologies such as annular closure devices and annular repair techniques have been investigated for reducing the incidence of reherniation following primary discectomy.

\section{The suture-based device}

A suture wire is used to close the annular defect, which is relatively less invasive. The biomechanical strength is doubtful in large annular defects and patients with poor annular quality $[39,40]$.

a. Xclose technique: Bailey et al. demonstrated a $45 \%$ risk reduction of reoperation due to re-herniation [41]

b. Fiber wire sutures and PushLock implants technique

c. Jetting suture technique.

\section{Annular closure device}

a. Barricaid: Implanted in the disc space post-discectomy and it is anchored into one of the adjacent vertebral bodies. Parker et al. demonstrated a zero re-herniation rate, no complications, and a trend toward less disc height loss with the utilization of the Barricaid [42].

Annular repair is an active area of research. Many of these preliminary studies are industry-funded, and these devices are not the standard of care today. However, they hold promise for the future.

\section{Conclusion}

rLDH can be a challenging diagnostic and therapeutic problem. Many possible patient-related, disc-related, and surgery-related risk factors may predispose to $\mathrm{LDH}$; however, their individual contribution to the overall risk is still unclear. The diagnosis of rLDH hitches on the clinical presentation that has a clear correlation with post-operative MRI. However, the diagnosis is frequently complicated by varied and atypical symptoms. Besides, there is an inherent difficulty in interpreting an over sensitive investigation like MRI. Compared to primary disc herniation, conservative treatment is less likely to succeed in recurrent herniation, possibly due to the associated epidural fibrosis and scarring. Revision discectomy is usually the primary choice of surgery for the first recurrence. A fusion procedure can be considered for those who have repeated reherniations or significant associated back pain and instability.

\section{References}

1. Kim KT, Park SW, Kim YB. Disc height and segmental motion as risk factors for recurrent lumbar discherniation. Spine (Phila Pa 1976) 2009;34:2674-8.

2. Weinstein JN, Lurie JD, Tosteson TD, Skinner JS, Hanscom B, Tosteson AN, et al. Surgical vs nonoperative treatment for lumbar disk herniation: The Spine patient outcomes research trial (SPORT) observational cohort.JAMA 2006;296:24519.

3. McGirt MJ, Eustacchio S, Varga P, Vilendecic M, Trummer M, GorensekM, et al. A prospective cohort study of close interval computed tomography and magnetic resonance imaging after primary lumbar discectomy: Factors associated with recurrent disc herniation and disc height loss. Spine (Phila Pa 1976) 2009;34:2044-51.

4. Shin BJ. Risk factors for recurrent lumbar disc herniations. Asian Spine J 2014;8:211-5.

5. Carragee EJ, Spinnickie AO, Alamin TF, Paragioudakis S. A prospective controlled study of limited versus subtotal posterior discectomy: Short-term outcomes in patients with herniated lumbar intervertebral discs and large posterior annular defect. Spine (Phila Pa 1976) 2006;31:653-7.

6. Keskimaki I, Seitsalo S, Osterman H, Rissanen P. Reoperations after lumbar disc surgery: A population-based study of regional and interspecialty variations. Spine 2000;25:1500-8.

7. Erbayraktar S, Acar F, Tekinsoy B, Acar U, Güner EM. Outcome analysis of reoperations after lumbar discectomies: A report of 22 patients. Kobe J Med Sci 2002;48:33-41.

8. Shimia M, Babaei-Ghazani A, Sadat BE, Habibi B, Habibzadeh A. Risk factors of recurrent lumbar disk herniation. Asian JNeurosurg 2013;8:93-6.

9. Jansson KA, Nemeth G, Granath F, Blomqvist P. Surgery for herniation of a lumbar disc in Sweden between 1987 and 1999: An analysis of 27,576 operations. J Bone Joint Surg Br 2004;86:841-7.

10. Kim KT, Lee DH, Cho DC, Sung JK, Kim YB. Preoperative risk factors for recurrent lumbar disk herniation in L5-S1. J Spinal Disord Tech 2015;28:E5717.

11. Meredith DS, Huang RC, Nguyen J, Lymas S. Obesity increases the risk of recurrent herniated nucleus pulposus after lumbar microdiscectomy. Spine J 2010;10:575-80.

12. Akmal M, Kesani A, Anand B, Singh A, Wiseman M, Goodship A. Effect of nicotine on spinal disc cells: A cellular mechanism for disc degeneration. Spine (PhilaPa 1976) 2004;29:568-75.

13. Andersen SB, Smith EC, Støttrup C, Carreon LY, Andersen MO. Smoking is an independent risk factor of reoperation due to recurrent lumbar disc herniation. Glob Spine J2018;8:378-81.

14. Miwa S, Yokogawa A, Kobayashi T, Nishimura T, Igarashi $\mathrm{K}$, Inatani $\mathrm{H}$, et al. Risk factors of recurrent lumbar disk herniation: A single center study and review 
of the literature.J SpinalDisord Tech 2015;28:E265-9.

15. Robinson D, Mirovsky Y, Halperin N, Evron Z, Nevo Z. Changes in proteoglycans of intervertebral disc in diabetic patients. A possible cause of increased back pain. Spine (PhilaPa 1976) 1998;23:849-56.

16. Mobbs RJ, Newcombe RL, Chandran KN. Lumbar discectomy and the diabetic patient: Incidence and outcome.JClin Neurosci2001;8:10-3.

17. Seidler A, Bolm-Audorff U. Occupational risk factors for symptomatic lumbar discherniation; a case-control study. Occup Environ Med 2003;60:821-30.

18. Yaman ME, Kazanci A, Yaman ND, Bas F, Ayberk G. Factors that influence recurrent lumbar discherniation. Hong Kong MedJ 2017;23:258-63.

19. Morgan-Hough CV, Jones PW, Eisenstein SM. Primary and revision lumbar discectomy: A 16-year review from one centre.J Bone Joint Surg Br 2003;85:8714.

20. Belykh E, Krutko AV, Baykov ES, Griers MB, Preul MC, Byvaltsev VA. Preoperative estimation of disc herniation recurrence after microdiscectomy: Predictive value of a multivariate model based on radiographic parameters. Spine J2017;17:390-400.

21. Hou T, Zhou Q, Dai F, Luo F, He Q, Zhang J, et al. Repeated microendoscopic discectomy for recurrent lumbar disk herniation. Clinics (Sao Paulo) 2015;70:120-5.

22. Pfirrmann CW, Metzdorf A, Zanetti M, Hodler J, Boos N. Magnetic resonance classification of lumbar intervertebral disc degeneration. Spine 2001;26:1873-8.

23. Ahlgren BD, Vasavada A, Brower RS, Lydon C, Herkowitz HN, Panjabi MM. Annular incision technique on the strength and multidirectional flexibility of the healing intervertebral disc. Spine 1994;19:948-54.

24. Ellenbogen JR, Marlow W, Fischer BE, Tsegaye M, Wilby MJ. Is the rate of reoperation after primary lumbar microdiscectomy affected by surgeon grade or intraoperative lavage of the disc space? BrJNeurosurg 2014;28;247-51.

25. Newsome RJ, May S, Chiverton N, Cole AA. A prospective, randomised trial of immediate exercise following lumbar microdiscectomy: A preliminary study. Physiotherapy 2009;95:273-9.

26. Licina P, Johnston E. Recurrent disc herniation-diagnosis and management. In: Lumbar Spine Online Tax Book, Section 18. Ch. 2. Spine: International Society for the Study of the Lumbar Spine; ???

27. van de Kelft EJ, van Goethem JW, de La Porte C, Verlooy JS. Early postoperative gadolinium-DTPA-enhanced MR imaging after successful lumbar discectomy. $\mathrm{Br}$ JNeurosurg 1996;10:41-9.

28. Van Goethem JW, Salgado R. Imaging of the postoperative Spine: Discectomy and herniectomy. In: Van Goethem JW, van den Hauwe L, Parizel PM, editors. Spinal Imaging, Medical Radiology (Diagnostic Imaging). Berlin, Heidelberg: Springer; 2007.

29. Shafaie FF, Bundschuh C, Jinkins JR. The posttherapeutic lumbosacral spine. In: Jinkins JR, editor. Postherapeutic Neurodiagnostic Imaging. Philadelphia, PA: Lippincott-Raven; 1997.p.245-66.

30. Swartz KR, Trost GR. Recurrent lumbar disc herniation. Neurosurg Focus 2003; 15:E10.

31. Cheng J, Wang H, Zheng W, Li C, Wang J, Zhang Z, et al. Reoperation after lumbar disc surgery in two hundred and seven patients. Int Orthop 2013;37:1511-7.

32. Ahsan K, Najmus-Sakeb, Hossain A, Khan SI, Awwal MA. Discectomy for primary and recurrent prolapse of lumbar intervertebral discs. J Orthop Surg (Hong Kong) 2012;20:7-10.

33. Chen HC, Lee CH, Wei L, Lui TN, Lin TJ. Comparison of percutaneous endoscopic lumbar discectomy and open lumbar surgery for adjacent segment degeneration and recurrent disc herniation. Neurol Res Int 2015;2015:791943.

34. Kim CH, Chung CK, Sohn S, Lee S, Park SB. The surgical outcome and the surgical strategy of percutaneous endoscopic discectomy for recurrent disk herniation.J Spinal Disord Tech 2014;27:415-22.

35. Mehren C, Wanke-Jellinek L, Korge A. Revision after failed discectomy. Eur Spine J2020;29:14-21.

36. Albayrak S, Ozturk S, Durdag E, Ayden O. Surgical management of recurrent disc herniations with microdiscectomy and long-term results on life quality: Detailed analysis of 70 cases. J Neurosci Rural Pract 2016;7:87-90.

37. Li Z, Tang J, Hou S, Ren D, Li L, Lu X, et al. Four-year follow-up results of transforaminal lumbar interbody fusion as revision surgery for recurrent lumbar disc herniation after conventional discectomy. J Clin Neurosci 2015;22:331-7.

38. Mroz TE, Lubelski D, Williams SK, O'Rourke C, Obuchowski NA, Wang JC, et al. Differences in the surgical treatment of recurrent lumbar disc herniation among spine surgeons in the United States. Spine J2014;14:2334-43.

39. Qi L, Li M, Si H, Wang L, Jiang Y, Zhang S, et al. The clinical application of jetting suture technique in annular repair under microendoscopic discectomy: A prospective single-cohort observational study. Medicine 2016;95:e4503.

40. Suh BG, Uh JH, Park SH, Lee GW. Repair using conventional implant for ruptured annulus fibrosus after lumbar discectomy: Surgical technique and case series. Asian Spine J2015;9:14-21.

41. Bailey A, Araghi A, Blumenthal S, Huffmon GV, Annular Repair Clinical Study Group. Prospective, multicenter, randomized, controlled study of annular repair in lumbar discectomy: Two year follow-up. Spine 2013;38:1161-9.

42. Parker SL, Grahovac G, Vukas D, Vilendecic M, Ledic D, McGirt MJ, et al. Effect of an annular closure device (Barricaid) on same level recurrent disc herniation and disc height loss after primary lumbar discectomy: Two-year results of a multicenter prospective cohort study. J Spinal Disord Tech 2013;???:???.

43. Sonmez E, Coven I, Sahinturk F, Yilmaz C, Caner H. Unilateral percutaneous pedicle screw instrumentation with minimally invasive TLIF for the treatment of recurrent lumbar disk disease: 2 years follow-up. Turk Neurosurg 2013;23:3728 .

44. El Shazly AA, El Wardany MA, Morsi AM. Recurrent lumbar disc herniation: A prospective comparative study of three surgical management procedures. Asian $J$ Neurosurg 2013;8:139-44.

45. Qiao G, Feng M. Revision for endoscopic discectomy: Is lateral lumbar interbody fusion an option? World Neurosurg 2020;133:e26-30.

46. Kapetanakis S, Gkantsinikoudis N, Charitoudis G. The role of full-endoscopic lumbar discectomy in surgical treatment of recurrent lumbar disc herniation: A health-related quality oflife approach. Neurospine 2019;16:96-104.

47. Cao J, Huang W, Wu T, Jia J, Cheng X. Percutaneous endoscopic lumbar discectomy for lumbar disc herniation as day surgery-short-term clinical results of 235 consecutive cases. Medicine (Baltimore) 2019;98:e18064.

48. Jung YS, Choi HJ, Kwon YM. Clinical outcome and influencing factor for repeat lumbar discectomy for ipsilateral recurrent lumbar disc herniation. Korean $J$ Spine 2012;9:1-5.

49. Zhang S, Chen H. Mini-open transforaminal lumbar interbody fusion through a modified wiltse paraspinal approach for recurrent lumbar disc herniation. Int $J$ Clin Exp Med 2019;12:2525-31.

50. Ahmed OE, Morad SH, Abdelbar AS. Management of recurrent unilateral lumbar disc herniation in a single level: Unilateral versus bilateral pedicle screws fixation with interbody fusion. Egypt J Neurol Psychiatry Neurosurg 2020;56:28. 


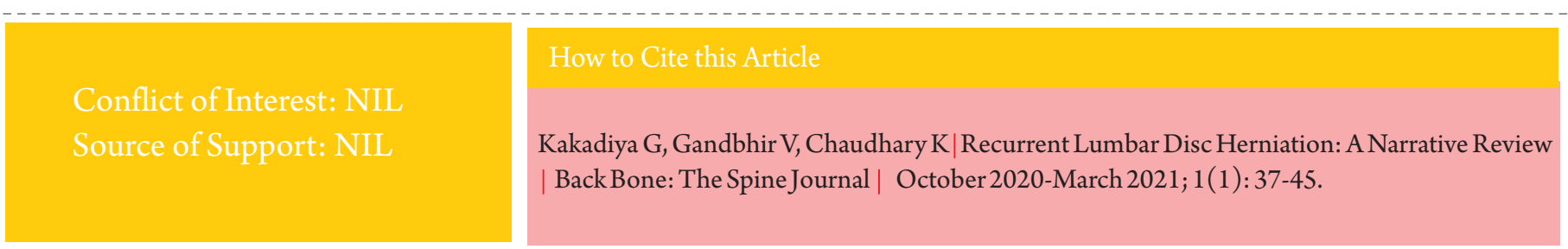

